\title{
EFFECT OF PREDUCTAL IN PATIENTS WITH COR ANAEMICUM: ASSESSMENT OF MYOCARDIAL PERFUSION
}

\author{
Georgieva Zh. ${ }^{1}$, A. Klisarova ${ }^{2}$ \\ ${ }^{1}$ Department of Propedeutics of Internal Medicine, Medical University of Varna, \\ ${ }^{2}$ Department of Nuclear Medicine, Medical University of Varna
}

\begin{abstract}
Nowadays anaemia affects a great part of the population worldwide. This problem is particularly significant because of its medical, social and economic aspects. The aim of this study was to establish the changes in myocardial perfusion after treatment with preductal in patients with chronic anaemia. The study covered 45 female patients at a mean age of $39,95 \pm 4,25$ years. Echocardiographic and single-photon emission computer tomographic examinations were performed. Left ventricular size and volume and cardiac output were increased but ejection fractions and fractions of shortening were decreased prior to preductal treatment. Scintigraphy revealed an increase of the left ventricular size and thinning of the myocardium in $26,66 \%$ of the cases. There were hypoperfusion areas in $62,22 \%$ of the cases. After a 3-month preductal treatment, any changes were completely reversed and any echocardiographic parameters normalized. Hyperdynamic heart regimen increased left ventricular volume and myocardial hypoperfusion under the conditions of chronic anaemic hypoxia in patients with severe anaemia of different types. Three-month-long preductal treatment caused a complete recovery of myocardial alterations.
\end{abstract}

Key words: chronic anaemia, preductal, echocardiography, SPECT, hypoperfusion

\section{INTRODUCTION}

The incidence of anaemia is global in its nature and affects population in working capacity. It is particularly significant because of its medical, social and economic aspects. In the last two decades haematologists report about a progressive decrease in the values of the population's haemoglobin and erythrocytes worldwide. Scientists appeal for improvement of haemoglobin health and prevention of cor anaemicum (1). They try to establish the initial changes in the functional and morphological structure of the heart as well as the time of recovery after treatment in patients with chronic anaemia (3). Researchers are also interested to find out in what cases myocardiodystrophy results from these anaemias (5).

The study aimed at establishing the changes in myocardial perfusion after treatment with preductal in patients with chronic anaemia.

\section{MATERIAL AND METHODS}

Forty-five female patients at a mean age of $39,95 \pm 4,25$ years were covered in the study. Table 1 shows their distribution according to the type of anaemia. All the patients

Address for correspondence:

Zh. Georgieva, Dept. of Propedeutics of Internal Medicine,

Medical University of Varna,

55 Marin Drinov Str., Varna 9002, Bulgaria

e-mail: zhana_georgieva@abv.bg suffered from a severe anaemia with haemoglobin levels of $61,72 \pm 2,6 \mathrm{~g} / \mathrm{L}$. They underwent echocardiography using standard methods for detecting the functional and structural myocardial changes before and after the treatment with preductal. The following patterns of left ventricular size and volume were reported: telediastolic and telesystolic sizes and left ventricular volumes, respectively (LVIDD, LVIDS, EDV, ESV), cardiac output (CO), ejection fraction (EF in \%), fraction of shortening (FS in \%), posterior wall thickness (PWT), interventricular wall thickness (IVWT), as well as left ventricular mass (LVM) calculated after Devereux's formula (4).

All the patients underwent a single-photon emission computer tomography (SPECT) following an intravenous injection of $2 \mathrm{mCi}$ TL-201 Cl in stress and $1 \mathrm{mCi}$ at rest before the beginning of the treatment and three months later on. The scintigraphic imaging revealed the perfusion of the

Table 1. Patients' distribution according to the type of anaemia

\begin{tabular}{||l|c|c||}
\hline \hline \multirow{2}{*}{ Type of anaemia } & \multicolumn{2}{|c||}{ Patients } \\
\cline { 2 - 3 } & $\mathrm{n}$ & $\%$ \\
\hline iron deficiency anaemia & 23 & 51,11 \\
\hline thalassaemia & 10 & 22,22 \\
\hline haemolytic anaemia & 12 & 26,67 \\
\hline total & 45 & 100,00 \\
\hline \hline
\end{tabular}


Effect of preductal in patients with cor anaemicum: assessment of myocardial perfusion

Table 2. Echocardiographic results

\begin{tabular}{||l|c|c|c||}
\hline \hline Parameter & $\begin{array}{c}\text { Before } \\
\text { treatment }\end{array}$ & $\begin{array}{c}\text { After } \\
\text { treatment }\end{array}$ & p \\
\hline LVIDD & $5,93 \pm 0,25$ & $4,66 \pm 0,22$ & $\mathrm{p}<0,001$ \\
\hline LVIDS & $4,28 \pm 0,17$ & $3,19 \pm 0,13$ & $\mathrm{p}<0,001$ \\
\hline EDV & $199,89 \pm 12,3$ & $98,97 \pm 8,2$ & $\mathrm{p}<0,001$ \\
\hline ESV & $79,88 \pm 8,03$ & $32,05 \pm 5,4$ & $\mathrm{p}<0,001$ \\
\hline SV & $118,42 \pm 8,67$ & $68,03 \pm 7,88$ & $\mathrm{p}<0,001$ \\
\hline FS (in \%) & $29,07 \pm 3,25$ & $32,03 \pm 3,42$ & $\mathrm{p}<0,002$ \\
\hline EF (in \%) & $56,29 \pm 4,85$ & $62,05 \pm 3,77$ & $\mathrm{p}<0,002$ \\
\hline CO & $9,92 \pm 1,43$ & $5,59 \pm 0,93$ & $\mathrm{p}<0,001$ \\
\hline LVM (g) & $246,85 \pm 31,09$ & $164,08 \pm 24,79$ & $\mathrm{p}<0,001$ \\
\hline IVWT $(\mathrm{cm})$ & $1,04 \pm 0,13$ & $0,94 \pm 0,09$ & $\mathrm{p}<0,01$ \\
\hline PWT & $1,03 \pm 0,12$ & $0,93 \pm 0,08$ & $\mathrm{p}<0,01$ \\
\hline \hline
\end{tabular}

left ventricle along the short axis, the horizontal long axis and the vertical long axis under stress conditions and at rest. The examination was performed in the morning before meals, the patient lying down with the left hand lifted upwards. The parameters of the acquisition protocol were the following: high-resolution collimator, matrix 64/64, $32 \mathrm{im}-$ ages, $30 \mathrm{sec} / \mathrm{image}$, head rotation $180^{\circ}$, initial position $45^{\circ}$, unzoomed image.

The patients were treated according to the following scheme: preductal (trimetazin) of one tablet 3 times daily, haemotransfusion for anaemic compensation and drugs for

Table 3. Scintigraphic results

\begin{tabular}{||c|c|c|c|c||}
\hline \hline \multirow{2}{*}{ Perfusion areas } & \multicolumn{2}{|c|}{ Hypopefusion areas } & \multicolumn{2}{|c|}{$\begin{array}{c}\text { Normal scintigraphic } \\
\text { imaging }\end{array}$} \\
\cline { 2 - 5 } & $\mathrm{n}$ & $\%$ & $\mathrm{n}$ & $\%$ \\
\hline before treatment & 28 & 62,22 & 17 & 37,78 \\
\hline after treatment & 0 & 0 & 45 & 100,00 \\
\hline \hline
\end{tabular}

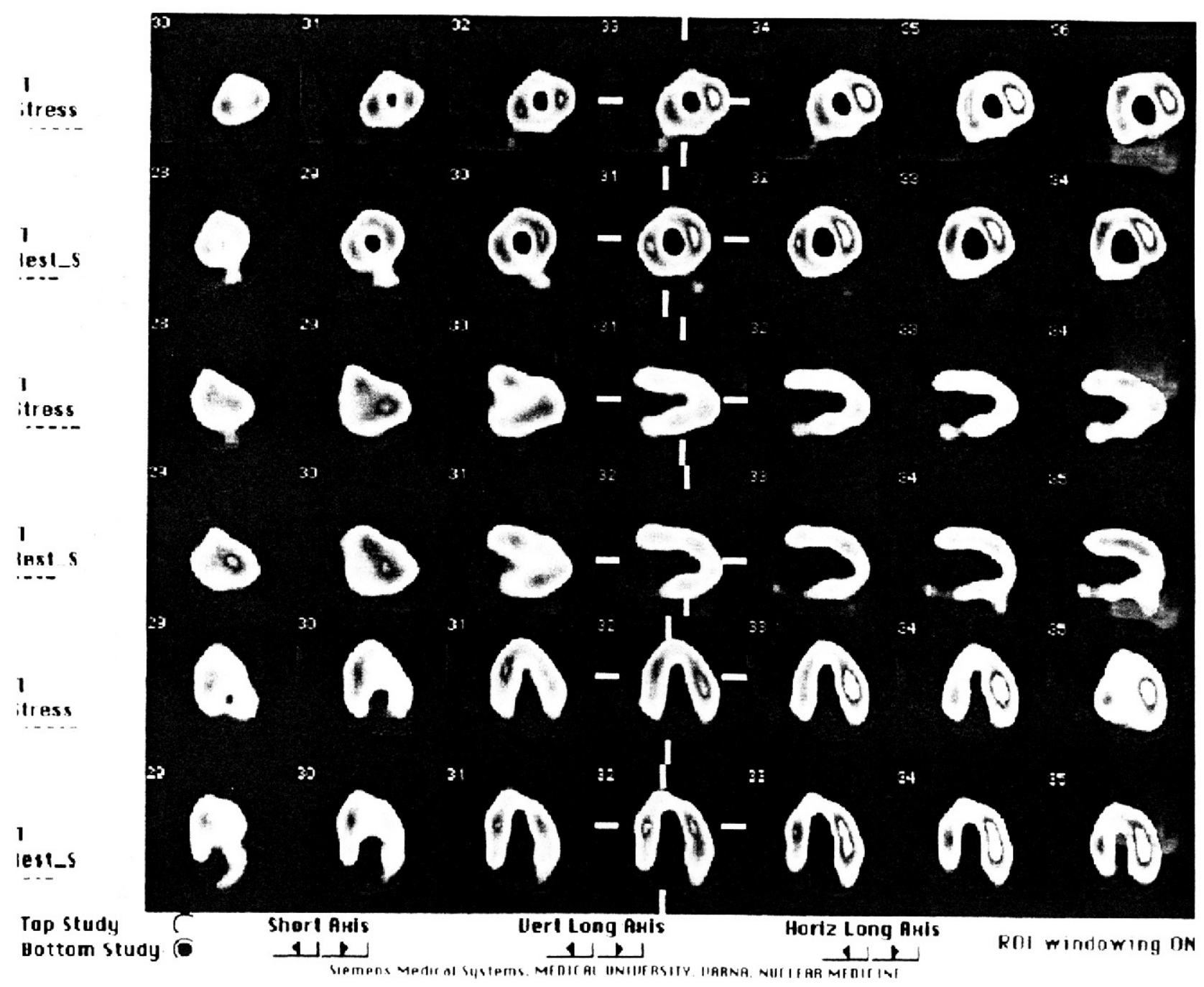

Fig. 1a. SPECT imaging in a female patient with iron deficiency anaemia 
iron deficiency compensation in the patients with iron deficiency anaemia.

\section{RESULTS}

Table 2 shows the results from the echocardiographic investigations before and after preductal treatment.

Prior to treatment, there was a marked increase of left ventricular size and volume, a significant CO increase determining a hyperdynamic working regime of the heart and a pronounced left ventricular dilatation. Both EFs and FSs were decreased and the thickness of the walls increased, yet, within the limits of the reference values. LVM enlarged at the expense of the left ventricular dilatation. After a 3-month preductal treatment, any changes were completely reversed and any echocardiographic parameters reached their normal values.

Table 3 shows the results from the scintigraphic imaging before and after preductal treatment. An increase of the left ventricular size and thinning of the myocardium was observed in 12 patients (in $26,66 \%$ of the cases). These results corresponded to the echocardiographic findings. After a 3-month preductal treatment the normal scintigraphic imaging was recovered in all the patients (Fig. 1a).

Hypoperfusion areas before preductal treatment were established in 28 patients (in $62,22 \%$ of the cases). The degree of hypoperfusion was below $50 \%$ in all the patients which was evident on the polar maps (Fig. 1b).

\section{DISCUSSION}

It is known that the subendocardium of the left ventricle is insufficiently blood supplied and thus more susceptible to anaemic hypoxia. This accounts for the hypoperfusion areas of the scintigraphic imaging under the anaemic condition. Sometimes the anaemic hypoperfusion areas can resemble hypoperfusion areas in chronic coronary artery disease resulting from reduced myocardial perfusion under such anaemic conditions $(6,7,9)$.

Our study reports normal echocardiographic parameters and normal myocardial perfusion three months after preductal treatmenth. This enables to assume that the recovery from anaemic hypoxia is faster than ischaemic hypoxia in patients with chronic coronary artery disease.

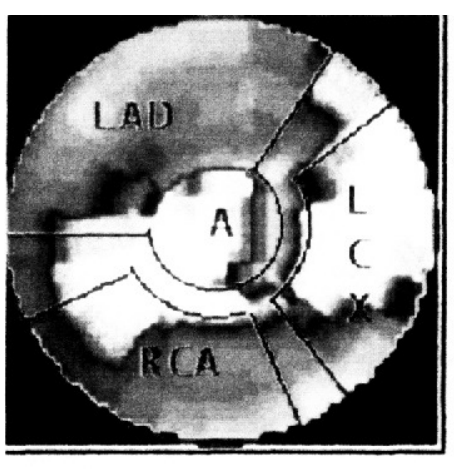

Stress
Stress

Palar Map of Tl-201 Activity in the Left

ventricle
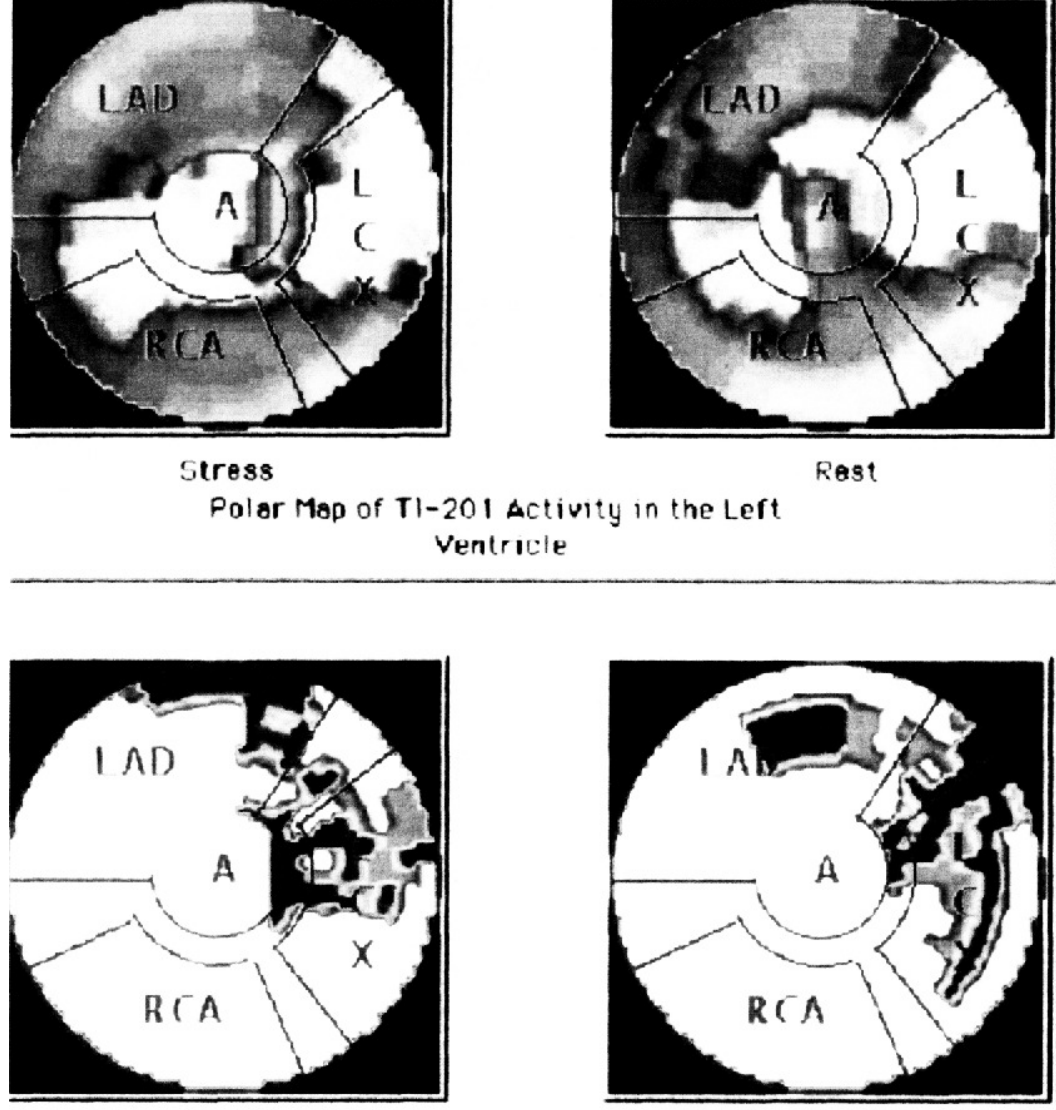

Rest

Extent of Derect Mop

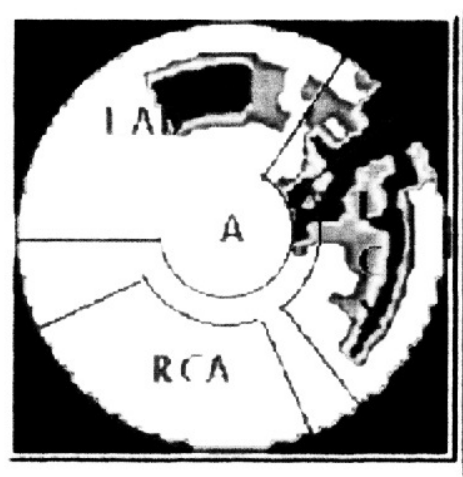

Rest
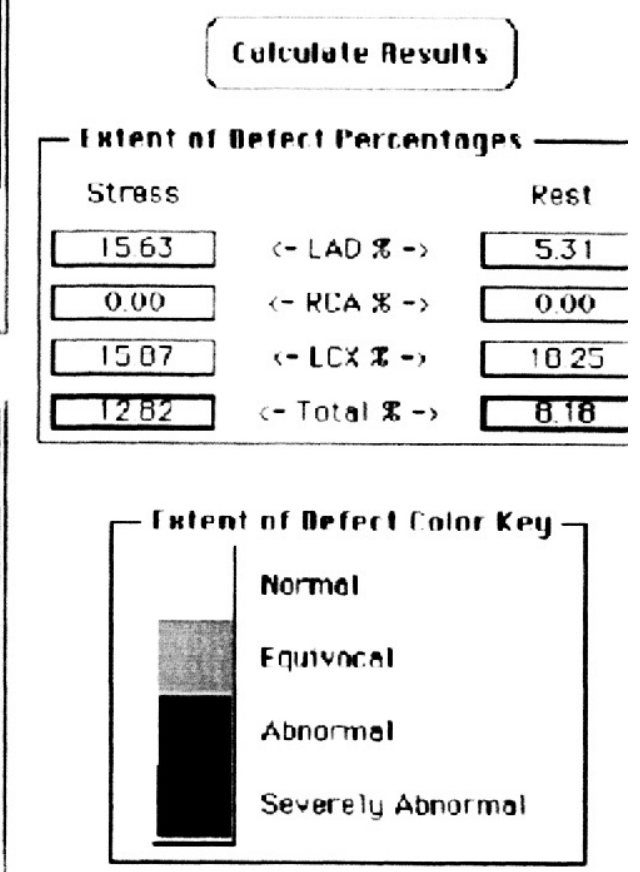

C Norimals Databnse wspl Empty OB CTQ

Fig. 1b. Polar maps in the same female patient 
Preductal regulates heart metabolism by suppressing the beta-oxygenation of the fatty acids. It preserves the cell energy metabolism by preventing the decrease of ATF levels, thus facilitating transmembrane transportation and cell homeostasis under hypoxia (2). This transportation of oxygen to the myocardial cells is disordered under conditions of anaemic hypoxia (8). Therefore, being aware of the mechanism of preductal action, we followed-up the reversibility of the myocardial changes after treatment with this drug for a period of three months.

\section{CONCLUSIONS}

Based on the present study, the following conclusions could be drawn:

1. Hyperdynamic heart regimen increased left ventricular volume and myocardial hypoperfusion as established under the conditions of chronic anaemic hypoxia in patients with severe anaemia of different types.

2. A three-month treatment with Preductal resulted in a complete recovery of myocardial alterations.

\section{REFERENCES}

1. Dallman, P. R. Iron deficiency: does it matter?- $J$. Intern. Med., 226, 1989, No 5, 367-372.

2. Detry, J. M., P. Sellier, S. Pennaforte, D. Cokkinos, H. Dargie, P. Mathes. Trimetazidine: a new concept in the treatment of an- gina. Comparison with propranolol in patients with stable angina. Trimetazidine European Multicenter Study Group.- Br. J. Clin. Pharmacol., 37, 1994, No 3, 279-288.

3. Capasso, J. M., T. Palackal, G. Olivetti, P. Anversa. Severe myocardial dysfunction induced by ventricular remodeling in aging rat hearts.- $A m$. $J$. Physiol., 259, 1990, No 4, Pt 2, H1086-H1096.

4. Feigenbaum, H. Echocardigraphy. Philadelphia, Lea \& Fibiger, 1996. p. 695.

5. Finch, C. A., L. R. Miller, A. R. Inamdar, R. Person, K. Seiler, B. Mackler. Iron deficiency in the rat. Physiological and biochemical studies of muscle dysfunction.- J. Clin. Invest., 58, 1976, No 2, 447-453.

6. Leppo, J. A., D. J. Meerdink. Comparison of the myocardial uptake of a technetium-labeled isonitrile analogue and tallium.- Circ. Res., 65, 1989, No 3, 632-639.

7. Meerdink, DJ, Leppo JA. Comparison of hypoxia and ouabain effects on the myocardial uptake kinetiks of technetium $99 \mathrm{~m}$ hexakis 2-methoxyisobutyl isonitrile and Tl-201.- J. Nucl. Med., 30, 1989, No 9, 1500-1506.

8. Nolan, P., F. Marcus.- In: The heart. R. W. Alexander, R. C. Schlant, V. Fuster, eds. $9^{\text {th }}$ ed. New York, NY, McGraw-Hill Co, 1998, 1127-1137.

9. Sawada, S. G., K. C. Allman, O. Muzik, R. S. Beanlands, E. R. Wolfe Jr, M. Gross, et al. Positron emission tomography detects evidence of viability in rest technetium-99m sestamibi defects.- $J$. Am. Coll. Cardiol., 23, 1994, No 1, 92-98. 